\title{
Reação de porta-enxertos de videira a Pratylenchus brachyurus e Pratylenchus zeae
}

\author{
Heriksen H. Puerari ${ }^{1}$, Claudia R. Dias-Arieira ${ }^{1}$, Mara F. Moura ${ }^{2}$, Fabio Biela ${ }^{1}$, Fernando M. Chiamolera ${ }^{1}$ \\ \& Tatiana P.L. da Cunha ${ }^{3}$
}

'Departamento de Ciências Agrárias, Universidade Estadual de Maringá, 87020-900, Maringá, PR, Brasil; ${ }^{2}$ APTA/IAC, Av. Barão de Itapura 1481, Cx. Postal 28, 13012-970, Campinas, SP, Brasil; ${ }^{3}$ Universidade Estadual Paulista "Júlio de Mesquita Filho" UNESP-FCAV, 14884-900, Jaboticabal, SP, Brasil

Autor para correspondência: Claudia R. Dias-Arieira, e-mail: crdarieira@uem.br

\begin{abstract}
RESUMO
Nesse trabalho, o objetivo foi avaliar a reação de oito porta-enxertos de videira aos nematoides das lesões radiculares. As estacas dos porta-enxertos Kober, SO4, 101-14, R99, 420-A, Rupestris du Lot, Riparia do Traviú e Telek 5C, cedidas pelo Centro APTA de Frutas/IAC, foram plantadas em vasos contendo mistura de solo:areia na proporção 2:1 (v:v) e mantidas em casa de vegetação. Após quatro meses, os porta-enxertos foram inoculados com 1.200 espécimes de Pratylenchus brachyurus ou P. zeae, e o milho foi usado para comprovar a viabilidade do inóculo. Aos 180 dias após a inoculação, avaliou-se o número de nematoides por sistema radicular e em 100 $\mathrm{cm}^{3}$ de solo. O milho foi avaliado aos 90 dias após a inoculação e cada vaso recebeu uma nova planta, que foi avaliada juntamente com os porta-enxertos. No milho, as populações finais de P. brachyurus e P. zeae foram respectivamente iguais a 8.040 e 6.940 indivíduos. Todos os porta-enxertos comportaram-se como imunes a $P$. brachyurus e $P$. zeae, isto é, a população final dos nematoides e o fator de reprodução foram iguais a zero. Recuperaram-se seis e 11 espécimes de $P$. zeae nas amostras de solo cultivadas com os porta-enxertos Kober e 420-A, respectivamente. Conclui-se que os porta-enxertos estudados apresentam potencial para serem usados em áreas infestadas com esses nematoides das lesões.
\end{abstract}

Palavras-chave: Vitis spp., nematoides das lesões radiculares, resistência.

\begin{abstract}
Reaction of grapevine rootstocks to Pratylenchus brachyurus and Pratylenchus zeae

The aim of this study was to evaluate the reaction of eight grapevine rootstocks to root-lesion nematodes. Cuttings of the rootstocks Kober, SO4, 101-14, R99, 420-A, Rupestris du Lot, Riparia do Traviú and Telek 5C, provided by the Centro APTA de Frutas/IAC, were planted in 5-L pots containing a 2:1 (v:v) soil and sand mixture, and kept in greenhouse. After four months, they were inoculated with 1,200 specimens of Pratylenchus brachyurus or P. zeae. Maize was used for detecting the inoculum viability. After 180 days of the inoculation, the root systems of the plants were collected along with $100 \mathrm{~cm}^{3}$ soil for evaluating the number of nematodes. Maize plants were evaluated 90 days after inoculation and each pot received a new seedling, which was evaluated along with the rootstocks. All rootstocks exhibited immunity to $P$. brachyurus and $P$. zeae, because the final populations in the root systems and the reproduction factor were zero. It was recovered six and 11 specimens of $P$. zeae in samples from cultivated soil with Kober and 420-A rootstock, respectively. In the maize, the respective average populations of $P$. brachyurus and $P$. zeae were 8,040 and 6,940. The rootstocks are potentially valuable for infested areas.
\end{abstract}

Key words: Vitis spp., resistance, root-lesion nematode.

Mundialmente, estima-se que a ocorrência de fitonematoides em videira possa reduzir em 20 a $25 \%$ a produção anual de uvas (Raski \& Krusberg, 1984; Anwar et al., 2000). Nos parreirais brasileiros já foram relatados diferentes gêneros de fitonematoides que parasitam o sistema radicular causando distúrbios, tanto morfológicos quanto fisiológicos, sendo eles: Aorolaimus Sher (Sin. Peltamigratus), Aphelenchus Bastian, Longidorus (Micoletzky) Thorne \& Swanger, Meloidogyne Goeldi, Mesocriconema Andrássy, Pratylenchus Filipjev, Rotylenchulus Linford \& Oliveira, Tylenchulus Cobb e Xiphinema Cobb (Naves, 2005). Meloidogyne spp.,
Tylenchulus semipenetrans Cobb, Xiphinema spp. e Pratylenchus spp. são considerados os mais danosos para a cultura (Smith, 1982).

Dentre as espécies de Pratylenchus encontradas parasitando videiras, citam-se $P$. crenatus Loof, P. neglectus (Rensch) Filipjev \& Schuurmans Stekhoven, P. penetrans (Cobb) Filipjev \& Schuurmans Stekhoven, $P$. thornei Sher \& Allen e P. vulnus Allen \& Jensen (Anwar \& Van Gundy, 1989; Pinkerton et al., 1999; Téliz et al., 2007). Em alguns trabalhos, Pratylenchus spp. foram registrados associados à rizosfera de videiras; no entanto, as espécies do parasita não foram identificadas e a patogenicidade não foi avaliada 
(Petit, 1978; Rubiano \& Agudelo, 1995; Gomes et al., 2001; Gomes et al., 2009).

O controle desses parasitas é complexo e o uso de porta-enxertos resistentes é considerado um dos mais importantes métodos de manejo de nematoides na viticultura (Anwar et al., 2000). Contudo, os trabalhos de seleção de porta-enxertos com resistência aos nematoides das lesões radiculares concentram-se, principalmente, na seleção de materiais resistentes a $P$. vulnus (Pinochet et al., 1992; McKenry \& Anwar, 2006).

No Brasil, as espécies de nematoides das lesões radiculares de maior importância para a agricultura são Pratylenchus brachyurus (Godfrey) Filipjev \& Schuurmans Stekhoven e Pratylenchus zeae Graham. O primeiro se destaca pela ampla disseminação nas principais áreas de cultivo agrícola e pelos danos ocasionados ao algodão, soja, milho, etc. (Asmus, 2004), e P. zeae, pela alta frequência e elevada população nas áreas de produção de cana-deaçúcar, em diferentes regiões do país (Moura et al., 1999; Severino et al., 2010). Ambas as espécies também já foram assinaladas na rizosfera de videiras (Naves, 2005).

Considerando a expansão da viticultura para áreas de clima tropical, como a região do Vale do São Francisco, favorável aos principais nematoides das lesões radiculares que ocorrem no Brasil, a seleção de porta-enxertos resistentes a esses parasitas é muito importante para a obtenção de boa produtividade da cultura. Assim, objetivou-se avaliar a reação de oito porta-enxertos de videira a $P$. brachyurus e P. zeae.

As estacas dos genótipos Kober, SO4, 101-14, R99, 420-A, Rupestris du Lot, Riparia do Traviú e Telek 5C foram cedidas pelo Programa de Melhoramento Genético de Videiras da Agência Paulista de Tecnologia dos Agronegócios (APTA), do Instituto Agronômico de Campinas (IAC). Esses porta-enxertos foram enraizados em vasos com capacidade para $5 \mathrm{~L}$, contendo mistura de solo:areia na proporção 2:1 (v:v), previamente autoclavada $\left(120^{\circ} \mathrm{C} / 2 \mathrm{~h}\right)$, e mantidos em casa de vegetação da Universidade Estadual de Maringá, Campus Regional de Umuarama.

Após quatro meses, cada porta-enxerto foi inoculado com suspensão de 1.200 espécimes de $P$. brachyurus ou $P$. zeae. O inóculo foi obtido de populações puras dos nematoides multiplicadas em raízes de milho, em casa de vegetação, durante seis meses. A extração das raízes foi feita a partir da metodologia proposta por Coolen \& D'Herde (1972). A suspensão de nematoides foi calibrada para 300 nematoides $/ \mathrm{mL}$ e distribuída em quatro orifícios abertos ao redor dos porta-enxertos. Plantas de milho, 15 dias após a germinação, foram inoculadas para comprovar a viabilidade dos inóculos.

Decorridos 180 dias da inoculação, coletou-se o sistema radicular das plantas e $100 \mathrm{~cm}^{3}$ de solo para avaliação do número de nematoides. O milho foi avaliado aproximadamente aos 90 dias após a inoculação, devido ao desenvolvimento avançado das plantas. Cada vaso recebeu uma nova planta de milho, que foi avaliada juntamente com os porta-enxertos. Para a extração de nematoides da raiz utilizou-se a metodologia citada anteriormente. Adotouse a metodologia de Jenkins (1964) para a extração de nematoides do solo. As amostras obtidas foram avaliadas sob microscópio estereoscópico, utilizando câmara de Peters, contando-se todos os espécimes de Pratylenchus presentes em cada amostra. Com os dados obtidos determinouse o fator de reprodução $(\mathrm{FR}=\mathrm{Pf} / \mathrm{Pi}$, em que $\mathrm{FR}$, Pf e Pi correspondem ao fator de reprodução, população final e população inicial, respectivamente) e os porta-enxertos foram classificados como imunes $(\mathrm{FR}=0)$, resistentes $(0<F R<1)$ ou suscetíveis ( $F R \geq 1)$ (Oostenbrink, 1966). O experimento foi conduzido em delineamento inteiramente casualizado, com oito repetições.

Todos os porta-enxertos comportaram-se como imunes a $P$. brachyurus e $P$. zeae, uma vez que a população dos nematoides no sistema radicular dos genótipos avaliados e o FR foram iguais a zero. Apenas nas amostras de solo obtidas dos vasos onde se cultivou os porta-enxertos Kober e 420-A, recuperaram-se seis e 11 espécimes de $P$. zeae, respectivamente. No milho avaliado aos 90 dias, a população média de $P$. brachyurus foi de $8.040(\mathrm{FR}=6,7)$ e a de $P$. zeae igual a $6.940(\mathrm{FR}=5,8)$, comprovando a viabilidade dos inóculos. Nas amostras de milho avaliadas juntamente com as videiras, foram registradas médias de 434,5 e 936,5 espécimes de $P$. brachyurus e $P$. zeae, respectivamente. A retirada dos sistemas radiculares e de $100 \mathrm{~cm}^{3}$ de solo da rizosfera do milho aos 90 dias pode ter contribuído para a redução do inóculo nos vasos, resultando em valores menores na segunda avaliação.

Estudos visando à seleção de porta-enxertos com resistência aos nematoides $P$. brachyurus e $P$. zeae são muito importantes, visto haver poucas informações na literatura. Além disso, diferentes genótipos de videira podem apresentar comportamento variável frente a uma determinada espécie do fitoparasita, como já foi observado para outras espécies de Pratylenchus (Pinochet et al., 1992). No trabalho realizado por Pinochet et al. (1992), observouse que os porta-enxertos SO4 e 1103-P comportaramse como resistentes a $P$. vulnus, com FR variando de 0,1 a 0,8 ; contudo, o fator de reprodução em 41-B, Fercal e Ritcher 110 variou de 5,1 a 10,6, em uma clara indicação de suscetibilidade. Resultados semelhantes, para o mesmo nematoide, foram obtidos por McKenry \& Anwar (2006).

Outro aspecto relevante na seleção de porta-enxertos resistentes é que espécies de Pratylenchus encontramse amplamente disseminadas nas áreas de viticultura mundial. No levantamento realizado por Pinkerton et al. (1999), P. crenatus e P. neglectus foram encontrados em $80 \%$ das amostras analisadas; entretanto, em menor escala, $P$. penetrans também foi registrado durante o estudo. $\mathrm{Na}$ Espanha, além de $P$. neglectus e $P$. penetrans, outras espécies de Pratylenchus foram recuperadas do solo e raízes de videiras cultivadas em diferentes regiões, como P. thornei e $P$. vulnus, sendo esta última a mais frequente e em maior população (Téliz et al., 2007). No Brasil, no 
Rio Grande do Sul, Pratylenchus spp. foram associados a $40,9 \%$ de videiras com sintomas de definhamento, porém, sem comprovação da patogenicidade (Gomes et al., 2001). De acordo com Barbosa et al. (2010), as espécies Pratylenchus jordanenis Hashim, P. thornei, P. brachyurus e $P$. zeae já foram constatadas em levantamentos realizados em pomares vitícolas de Minas Gerais e do Rio Grande do Sul. Os autores destacaram ainda que nos parreirais do Submédio do Vale do São Francisco, P. brachyurus é a espécie mais comum.

Alguns porta-enxertos avaliados nesse trabalho também apresentaram resistência a Meloidogyne spp., tais como SO4, Kober, 101-14 e R99 (Kuhn \& Fajardo, 2003), fato importante, visto que a ocorrência de populações mistas do nematoide das lesões e o das galhas é frequente em áreas de cultivo de videiras (Pinkerton et al., 1999; McKenry \& Anwar, 2006; Téliz et al., 2007).

Nas condições em que o experimento foi realizado, todos os porta-enxertos apresentaram reação de imunidade a $P$. brachyurus e $P$. zeae, o que mostra a sua potencialidade para recomendação para áreas naturalmente infestadas com essas espécies de Pratylenchus. Contudo, é interessante estudá-los em campo, a fim de comprovar os resultados aqui obtidos.

\section{REFERÊNCIAS BIBLIOGRÁFICAS}

Anwar SA, McKenry MV, Faddoul F (2000) Reproductive variability of field populations of Meloidogyne spp. on grape rootstocks. Journal of Nematology 32:265-270.

Anwar SA, Van Gundy SD (1989) Influence of four nematodes on root and shoot growth parameters in grape. Journal of Nematology 21:276-283.

Asmus GL (2004) Ocorrência de nematóides fitoparasitos em algodoeiro no estado de Mato Grosso do Sul. Nematologia Brasileira 28:77-86.

Barbosa MAG, Castro JMC, Terao D, Lima MF, Batista DC, Tavares SCCH (2010) Cultivo da videira. Sistema de Produção 1. Petrolina PE. Embrapa Semiárido. Disponível em: http:// sistemasdeproducao.cnptia.embrapa.br/FontesHTML/Uva/ CultivodaVideira_2ed/doencas.html\#9. Acesso em: 23/05/2011.

Coolen WA, D'Herde CJ (1972) A method for the quantitative extraction of nematodes from plant tissue. Ghent Belgium. State Agriculture Research Center.

Gomes CB, Sonego OR, Campos AD, Almeida MRA, Sperândio CA (2001) Levantamento da nematofauna associada a rizosfera de videiras (Vitis sp.) na serra gaúcha. Nematologia Brasileira 25:123-124.

Gomes CB, Campos AD, Costa FA (2009) Levantamento de nematóides fitoparasitas associados a pomares de videira em declínio da Serra Gaúcha. Pelotas RS. Embrapa Clima Temperado. (Boletim de Pesquisa e Desenvolvimento no. 110).

Jenkins WR (1964) A rapid centrifugal-flotation technique for separation nematodes from soil. Plant Disease Reporter 48:692.

Kuhn GB, Fajardo TVM (2003) Doenças causadas por vírus, bactérias e nematóides e medidas de controle. Disponível em: http://sistemasdeproducao.cnptia.embrapa.br/ FontesHTML/Uva/ UvaAmericanaHibridaClimaTemperado/virus.htm. Acesso em: $12 / 05 / 2011$.

McKenry MV, Anwar SA (2006) Nematode and grape rootstock interactions including an improved understanding of tolerance. Journal of Nematology 38:312-318.

Moura RM, Pedrosa EMR, Maranhã SRVL, Moura AM, Macedo MEA, Silva EG (1999) Nematóides associados à cana-de-açúcar no Estado de Pernambuco, Brasil. Nematologia Brasileira 23:9299.

Naves RL (2005) Diagnose e manejo de doenças causadas por fitonematóides na cultura da videira. Bento Gonçalves RS. Embrapa Uva e Vinho - Estação Experimental de Viticultura Tropical. (Circular Técnica no 57).

Oostenbrink R (1966) Major characteristics of the relation between nematodes and plants. Mededeelingen der LandbouwHoogeschool 66:1-46.

Petit P (1978) Estudio preliminar sobre los nematodos fitoparasitos asociados al cultivo de la vid (Vitis vinifera L.) en Venezuela. Nematropica 8:66-68.

Pinkerton JN, Forge TA, Ivors KL, Ingham RE (1999) Plantparasitic nematodes associated with grapevines, Vitis vinifera, in Oregon vineyards. Journal of Nematology 31:624-634.

Pinochet J, Verdejo S, Soler AJ (1992) Host range of a population of Pratylenchus vulnus in comercial fruit, nut, citrus, and grape rootstocks in Spain. Journal of Nematology 24:693-698.

Raski DJ, Krusberg LR (1984) Nematode parasites of grapes and other small fruits. In: Nickle WR (Ed.) Plant and insect nematodes. New York EUA. Marcel Dekker. pp. 457-506.

Rubiano JA, Agudelo FV (1995) Identification and parasitism of nematodes of grape Vitis spp. Fitopatologia Colombiana 19:2735.

Severino JJ, Dias-Arieira CR, Tessmann DJ (2010) Nematodes associated with sugarcane in sandy soils in Paraná, Brazil. Nematropica 40:111-119.

Smith PC (1982) Nematodes pests of grapevines. Nematology in Southern Africa. Pretoria South Africa. Science Bulletin of the Department of Agriculture and Fisheries.

Téliz D, Landa BB, Rapoport HF, Pérez Camacho F, JiménezDíaz RM, Castillo P (2007) Plant-parasitic nematodes infecting grapevine in Southern Spain and susceptible reaction to root-knot nematodes of rootstocks reported as moderately resistant. Plant Disease 91:1147-1154. 